\title{
Historia natural de la leishmaniasis cutánea y mucocutánea
}

\author{
Carlos Arturo Hernández \\ Grupo de Parasitología, Instituto Nacional de Salud, Bogotá, D.C., Colombia.
}

\begin{abstract}
Las manifestaciones clínicas de la leishmaniasis cutánea y mucocutánea siguen siendo el primer paso para la sospecha de la infección y, por consiguiente, para su diagnóstico y obtención de muestras para su confirmación parasitológica. A pesar de ser una de las patologías parasitarias de mayor incremento en los últimos años en Colombia, no es fácil encontrar en la literatura imágenes de las lesiones clínicas y de su evolución. Por esta razón, y con el ánimo de brindarle imágenes de referencia al personal de salud que se enfrenta al diagnóstico de esta parasitosis, se presenta una serie de fotos que resumen la evolución del cuadro clínico desde los lesiones iniciales en el momento de la picadura de la hembra de Lutzomyia hasta las manifestaciones graves por destrucción de la mucosa nasal y oral.
\end{abstract}

Palabras clave: leishmaniasis cutánea, leishmaniasis mucocutánea, Colombia

\section{Natural history of cutaneous and mucocutaneous leishmaniasis}

The clinical picture of cutaneous and mucocutaneous leishmaniasis is still the first step in infection suspicion and, consequently, for its accurate diagnosis and sample obtention for parasitological confirmation. Even though leishmaniasis is the parasitic infection with the greatest increase in the last years in Colombia, it is difficult to find in the literature photographs of its clinical manifestations and evolution. For this reason, and hoping to offer a reference article for health personnel dealing frequently with this pathology, a series of pictures is presented that summarize the clinical picture and its evolution from the incipient lesion after the bite of a Lutzomyia female until the severe nasal and oral cartilaginous destruction.

Key words: leishmaniasis, cutaneous; leishmaniasis, mucocutaneous; Colombia

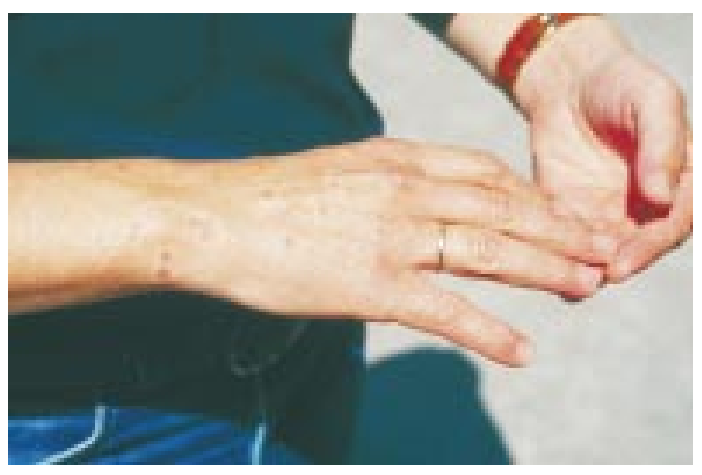

Correspondencia:

Carlos Arturo Hernández, Grupo de Parasitología, Instituto Nacional de Salud, Avenida calle 26 № 51-60, Bogotá, D.C., Colombia.

Pensionado de la institución desde 01/01/2006

Teléfono: (571) 2207700 , extensión 225.

cahch322@yahoo.com

Recibido: 01/07/06; aceptado: 01/08/06
Figura 1. Manchas eritematosas con ligero tinte violáceo que desaparecen a la vitropresión; aparecen poco tiempo después de la picadura de la hembra de Lutzomyia, sin importar si está infectada o si no lo está. Los pacientes refieren una sensación de "quemadura" o "pringue" en el momento de la picadura. 


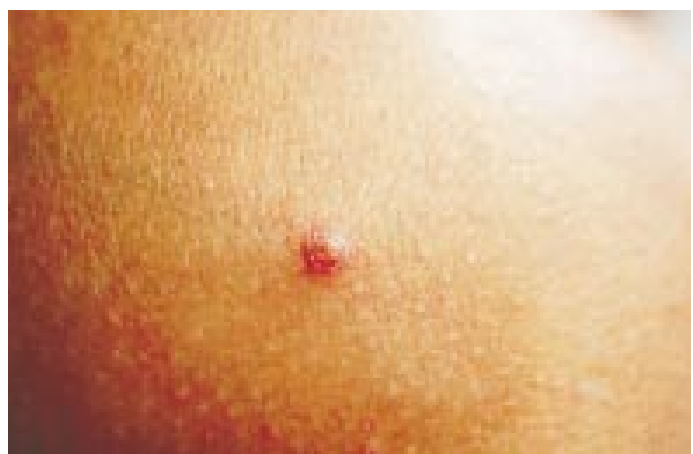

Figura 2. Entre los 3 y 8 días, aproximadamente, después de la picadura aparece una pequeña pápula indurada en el sitio de la picadura si hubo transmisión de promastigotes de Leishmania sp. Nótese que no hay eritema ni descamación de la piel alrededor de la lesión; además, el paciente no refiere ninguna sintomatología; no hay dolor, ni prurito, ni molestia alguna.

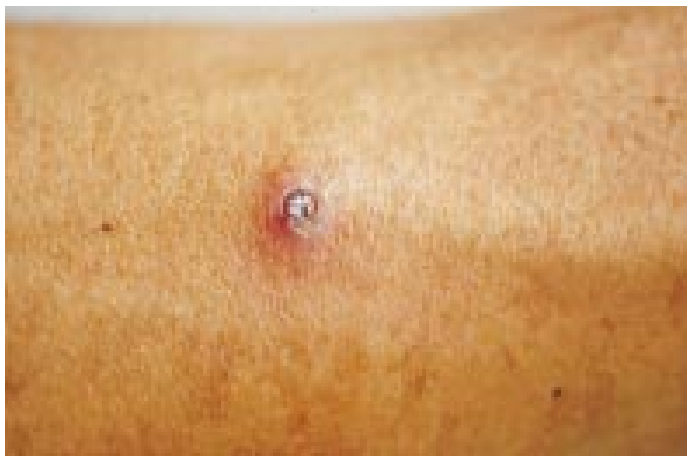

Figura 3. A las dos semanas, aproximadamente, después de la picadura, la lesión continúa su proceso de ulceración y la costra central es más evidente, al igual que la induración alrededor de la lesión. Los demás signos permanecen sin variación.

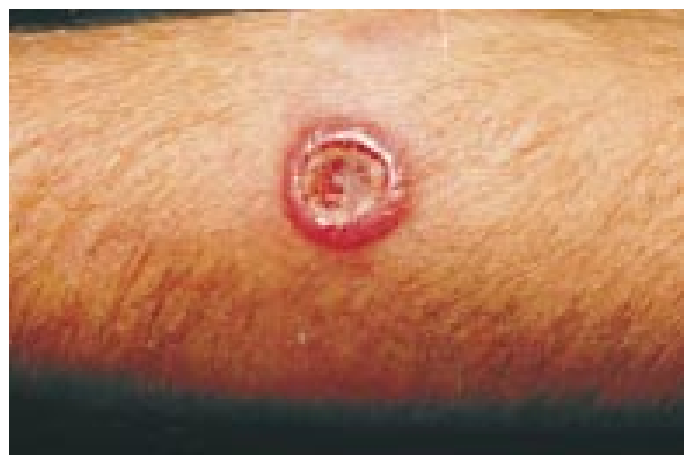

Figura 4. Hacia la tercera semana de evolución de la lesión ya aparece la imagen de la úlcera típica, la cual es simétrica, redondeada u ovalada, con bordes indurados y levantados, y fondo limpio de aspecto granulomatoso que sangra fácilmente; si no hay infección bacteriana ni micótica asociada el paciente no presenta eritema ni descamación de la piel.

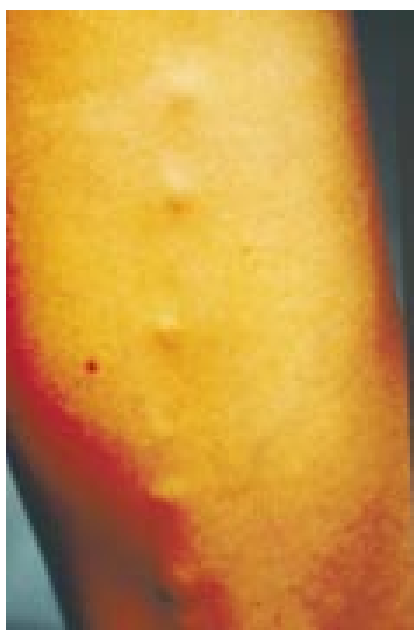

Figura 5. Ocasionalmente, se puede observar la presencia de linfadenopatías en el sitio de drenaje de la lesión, como fue el caso de este paciente con una lesión en el hombro derecho; la frecuencia de este hallazgo clínico todavía no se ha logrado precisar.

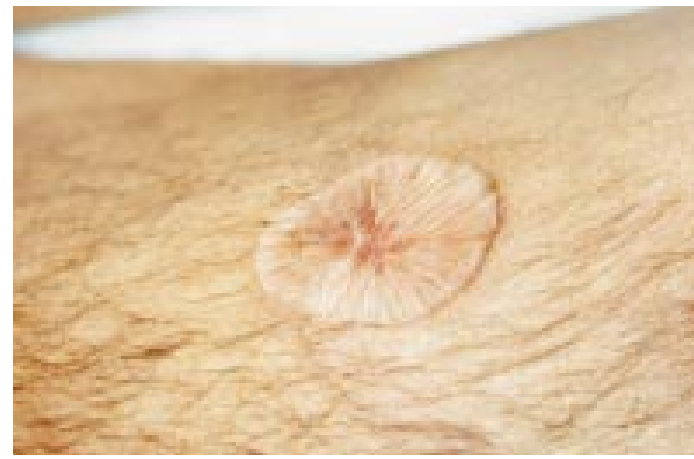

Figura 6. Cicatriz "típica" en la que se observa ligera hiperpigmentación, con presencia de líneas radiadas centrípetas y, necesariamente, de menor grosor que la piel normal dado el compromiso importante que hubo en la epidermis y en la dermis. 


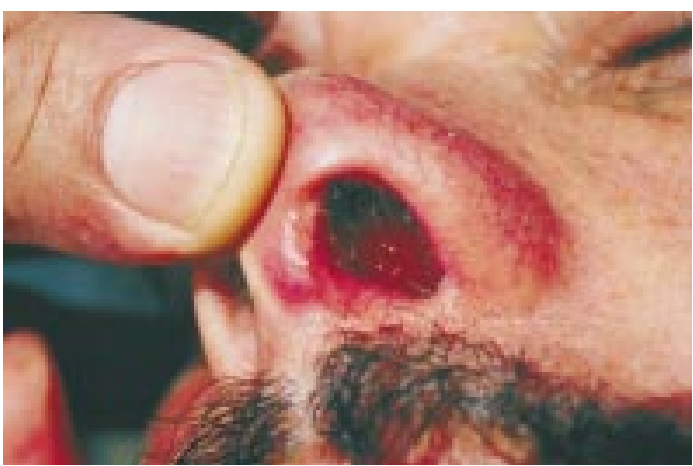

Figura 7. Una de las primeras manifestaciones del compromiso de la mucosa nasal es el enrojecimiento de la mucosa del tercio distal del tabique nasal. Es posible que el paciente consulte por epistaxis o rinorrea frecuentes, o por sensación de dificultad para respirar. El tiempo de aparición de este signo es totalmente impredecible con las técnicas que se cuenta en la actualidad.

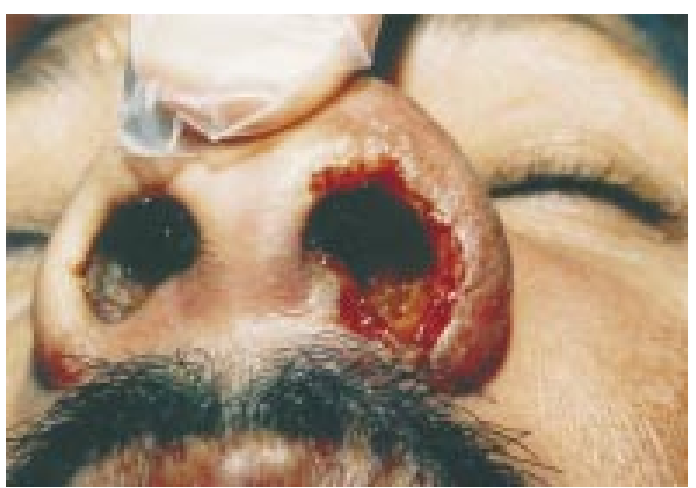

Figura 8. Posteriormente, se inicia un proceso de ulceración de la mucosa con ligera elevación e induración de los bordes de la lesión y, por consiguiente, epistaxis frecuente con el más leve estímulo mecánico.

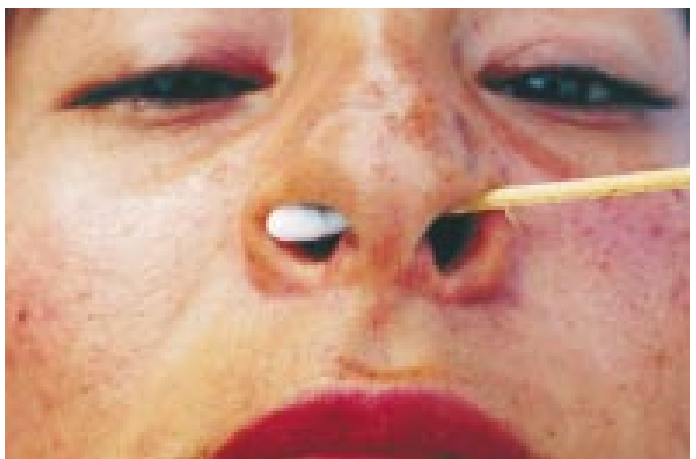

Figura 9. Algunos pacientes presentan, días o meses después, destrucción del soporte cartilaginoso de la nariz; en este caso, hubo perforación del tercio distal del tabique por una lesión cutánea en el dorso de la nariz para la cual la paciente no recibió tratamiento alguno.

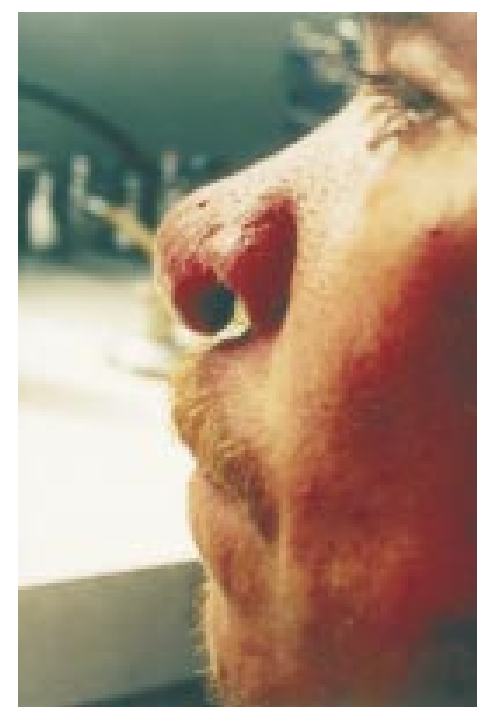

Figura 10. Si la lesión mucosa es más agresiva, el paciente puede presentar no sólo la deformación, el ensanchamiento y la perforación del tercio distal del tabique sino, también, la pérdida del soporte cartilaginoso de las aletas nasales y la consecuente caída de la punta nasal a la que se le conoce comúnmente como "nariz de tapir" o "pico de loro".

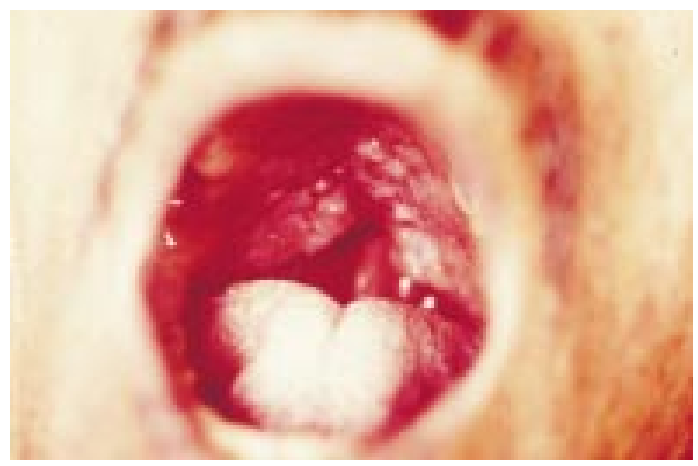

Figura 11. Si el compromiso es de la mucosa de la cavidad oral -menos frecuente que el de cavidad nasal- el paciente presenta pérdida de la úvula y compromiso de los velos del paladar, y el paladar duro tiene aspecto de "empedrado". El compromiso puede también extenderse a la mucosa de la laringe y la faringe e, incluso, a la de la tráquea superior.

\section{Conflicto de intereses}

El autor manifiesta que no tiene ningún tipo de conflicto de intereses. 